\title{
Area, isolation, disturbance and age effects on species richness of summer waterbirds in post-mining subsidence lakes, Anhui, China
}

\author{
Jin-Ming Zhao and Li-Zhi Zhou*
}

\begin{abstract}
Background: The species-area relationship is one of the best documented patterns in community ecology. Factors influencing species-area relationship are still not well understood. Since the proposal of the equilibrium theory of island biogeography, many studies have tested the effects of area and isolation, estimating effects of disturbance and patch age were scarce and should also be important bearing.

Methods: We investigated summer waterbird species richness in 38 post-mining subsidence lakes in Huainan and Fuyang, Anhui, China, May 25-June 12, 2016. We examined the effects of lake area, isolation (distance to natural water bodies), aquaculture disturbance, lake age and lake state (still sinking or not sinking) on summer waterbird species richness with multivariable linear regression method and model selection method.

Results: Our results from multivariable linear regression and model selection were consistent, which showed that species richness was positively related with lake area and negatively related with isolation. Aquaculture disturbance negatively influenced species richness. Highest species richness were found in lakes under intermediate intensity of aquaculture activities with area less than 100 ha and lakes under low intensity of aquaculture activities with area greater than 100 ha. Lake age and lake state had no significant effects on species richness.

Conclusions: Species richness was most related with lake area, aquaculture disturbance, and isolation, with lake area had a positive effect, while aquaculture activities and isolation had a negative effect. What's more, aquaculture activities significantly changed the slope of species-area relationship and might impede us finding a relationship between species richness and lake age.
\end{abstract}

Keywords: Species-area relationship, Aquaculture activity, Area size, Isolation, Species richness, Post-mining subsidence lakes

\section{Background}

Understanding how and why species richness varies over space and time is a major endeavor in ecology. One of the best documented patterns in community ecology is that species richness increases with area sampled, or the species-area relationship (Williamson 1988; Durrett and Levin 1996). Ecological theory provided

*Correspondence: zhoulz@ahu.edu.cn; zhoulz2009@qq.com School of Resources and Environmental Engineering, Anhui University, Hefei 230601, China three explanations for the increase of species richness with habitat area. The habitat heterogeneity hypothesis assumed that large areas tended to contain a greater diversity of environmental conditions, and thereby, supported more species (Connor and McCoy 1979). The sampling hypothesis assumed that the more species found in large areas was caused by a greater sampling effort in these areas (Rosenzweig 1995). In addition, MacArthur and Wilson (1967) proposed the outstanding equilibrium theory of island biogeography, predicted that species richness in island relied on the dynamic 
equilibrium of colonization and extinction processes, and species richness should increase with area size and decrease with distance from source pool. Increasing island size affected species richness primarily through increase in niche variety and population size, while isolation decreased species richness by reducing the number of potential colonists dispersing into the island (MacArthur and Wilson 1967; Rosenzweig 1995).

Since being proposed, the equilibrium theory of island biogeography had been applied to explain patterns of species richness observed not only for real islands (Economo et al. 2016), but also for such habitats as isolated forests (Ross et al. 2002; Rybicki and Hanski 2013), mountain tops (Frey et al. 2007), weed lots (Crowe 1979), and small artificial islands (Rejmánek and Rejmánková 2002). A remarkable point in these studies was that researchers usually assumed that all niches on islands had been occupied and maximum species richness had being reached (Bush and Whittaker 1991; Hubbell 1997). This assumption was not verified in all systems. Patch availability in fragmented landscapes or insular islands could vary as a consequence of time since patch or island formation (Valente et al. 2014). In such circumstances, the successful colonization by new species also depended on another factor in addition to area and isolation: the patch or island age (Horsák et al. 2012). Currently, investigations on the role of habitat age has been mainly limited to oceanic archipelagos across evolutionary time scales (Badano et al. 2005; Kreft et al. 2008; Valente et al. 2014). Few previous studies have investigated patchy inland systems (Krauss et al. 2009), which have been limited to short time scales.

Human disturbance is also an important ecological factor affecting species richness in natural environments (Fox and Fox 2000; Hiddink et al. 2006; Yuan et al. 2014). Disturbance can be considered as events that promote alteration in system structure, change species competition and resource availability (Sousa 1984). Increased levels of disturbance have been found producing decreased species richness in mammals and seabed benthic biomass (Fox and Fox 2000; Hiddink et al. 2006). Vera and Rocha (2006) also showed that the highest species diversity occurred in habitats with intermediate levels of disturbance frequency and intensity. Moreover, the effect of human disturbance on species richness can occur independently or along with the effects of spatial heterogeneity and patchiness (Tittensor et al. 2007). More studies are needed to simultaneously test the effects of patch area, age, isolation, and disturbance.

In this study, we studied the summer waterbird species-area relationship from 38 post-mining subsidence lakes in Huainan and Fuyang, Anhui province, China. These lakes had transformed from farms and villages through high groundwater influx after ground sinking caused by large amount deep coal mining from 1980s until now. These lakes, as ecosystems with well-circumscribed boundaries, were an aquatic equivalent to oceanic islands (Wagner et al. 2014), and thus gave us a good opportunity to test the area and isolation effects on species richness, and also the influences of lake age on species richness. Moreover, located in the most inhabited areas in China, these lakes were under intense human disturbance (i.e. aquaculture activity). So we also estimated the effects of different levels of aquaculture activities on species richness. In addition, we also tested the effect of lake state (still sinking or not sinking). We predicted that: (1) species richness would increase as lake area and lake age increasing; (2) species richness would be also higher for lakes not sinking compared with lakes still sinking; (3) species richness would decrease as isolation and intensity of aquaculture activity increase.

\section{Methods \\ Study area}

Our study area was 38 post-mining subsidence lakes in Huainan and Fuyang, Anhui, China. These lakes, located at an area of $140 \mathrm{~km}^{2}, 70 \mathrm{~km}$ from west to east $\left(116.14^{\circ}-116.87^{\circ} \mathrm{E}\right)$, and $20 \mathrm{~km}$ from south to north $\left(32.69^{\circ}-32.88^{\circ} \mathrm{N}\right)$, were formed because ground water and underground water flowed in the subsidence grounds after coals were mined from deep underground. This area belongs to temperate monsoon climate zone, with a mean annual temperature of $16.6^{\circ} \mathrm{C}$ and mean annual precipitation of $932.9 \mathrm{~mm}$ (Wan et al. 2015). As one of the most cultivated areas in China, natural habitats (i.e., forests, grasslands) have long been transformed to farms, villages and towns. There are abundant water resources, with high groundwater level in this area. Main rivers and natural lakes include Huai River, Ying River, Ji River, Xifei River, Ni River, Cihuaixin River, Jiaogang Lake, Xifei Lake, Chengbei Lake and Ni Lake (Fig. 1).

\section{Data collection}

We investigated summer waterbirds (Anseriformes, Gruiformes, Ciconiiformes, Charadriiformes and Lariformes) during May 25 to June 12, 2016. We considered each subsidence lake as a sample. To thoroughly record all waterbirds in each lake, we circled the lake by foot when its open water breadth $\geq 300 \mathrm{~m}$, and walked along the long side of the lake when its open water breadth $\leq 300 \mathrm{~m}$. We observed the birds using a binocular (SWAROVSKI $8.5 \times 42)$ and a telescope (SWAROVSKI $20 \times 60$ ). We recorded all waterbird individuals occurred at the lakes.

We calculated the 38 subsidence lake area sizes (ha) using application Google Earth. And isolation was calculated as the straight line distance $(\mathrm{m})$ between a 


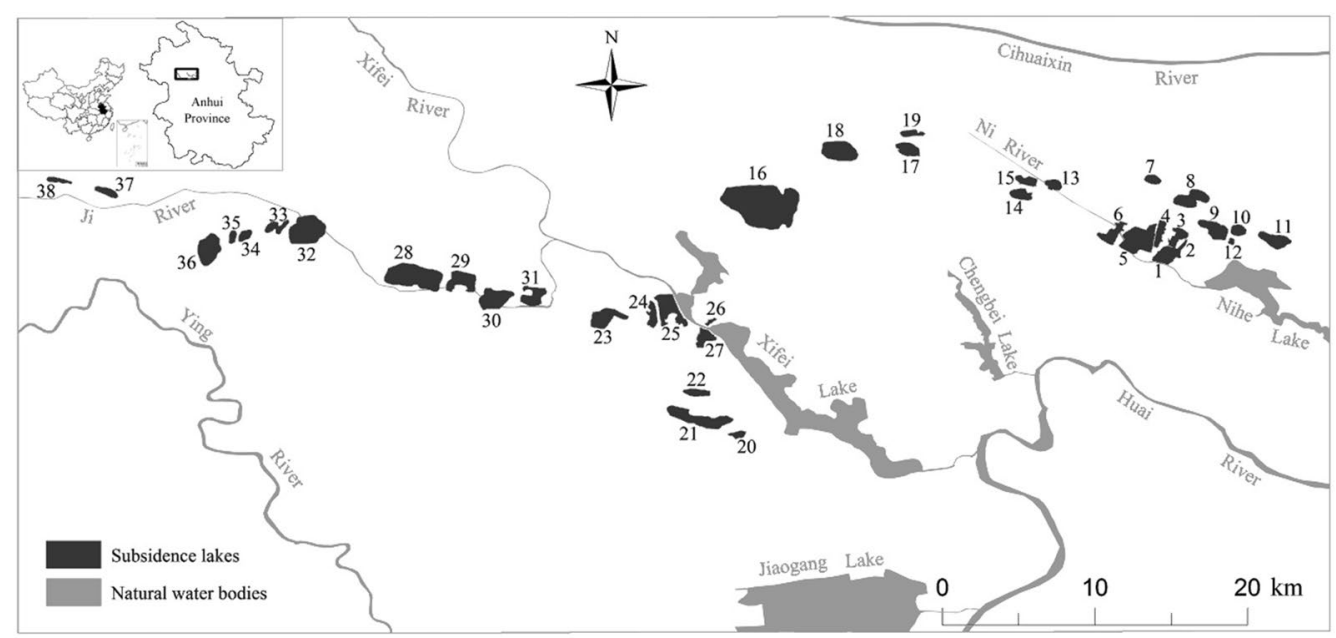

Fig. 1 Locations of the 38 post-mining subsidence lakes and surrounding natural water bodies in Huainan and Fuyang, Anhui, China

subsidence lake and the nearest source pool, which was arbitrarily defined as natural lakes or rivers with width $\geq 30 \mathrm{~m}$ (see Fig. 1). We calculated the lake age by subtracting the year of lake formation, which was obtained from local villagers or staff of coal mining company, from year 2016. Situated at the most populated areas in China, these lakes were under various human disturbances, such as fishing, irrigation, aquaculture, agriculture activities around the lakes. Among these human activities, aquaculture was a widely existed phenomenon in all lakes and had a direct impact on lakes' ecosystems because it occurred right in the lakes compared to all other activities that occasionally happened in some sites along the lake shores. We measured the extent of aquaculture in each subsidence lake as a representation of disturbance through estimating the percent of area occupied by fishing net or net cage. We defined as "low disturbance" when aquaculture area was $\leq 25 \%$ of open water in a lake, "intermediate disturbance" when $>25 \%$ and $\leq 50 \%$, "high disturbance" when $>50 \%$ (Additional file 1: Table S1). We also wanted to compare the waterbird differences between lakes still sinking and lakes with stable state (not sinking). We defined lakes still sinking as category " 1 " and lakes that did not sink in the previous year before our investigation as category "0" (Additional file 1: Table S1).

\section{Statistical analysis}

We calculated mean values of lake area, lake age, and isolation. We drew species accumulation curve to see whether our sample method was sufficient using rarefaction method in EstimateS software (Amato et al. 2013).

We tested the effects of area, isolation, disturbance, lake age and lake state on species richness using both multivariable linear regression method and model selection method. Before analysis, we tested multicollinearity between all five independent variables using Pearson correlations, and all variables were retained in the following analysis because all correlation coefficients were below 0.6 (Graham 2003). For multivariable linear regression, we included all independent variables in the regression and selected variables by stepwise method. For model selection method, we evaluated the relative support among a priori of 10 models which represented the effects of area, isolation, disturbance, lake age, lake state, and their combinations. We used Akaike's Information Criterion adjusted for small sizes $\left(\mathrm{AIC}_{\mathrm{c}}\right)$ and Akaike weights $\left(w_{i}\right)$ to evaluate the strength of evidence among competing models (Akaike 1973; Burnham and Anderson 2002). The most parsimonious model with the smallest $\mathrm{AIC}_{\mathrm{c}}$ value was considered to be the best model. The model weight $\left(w_{i}\right)$ was used to indicate the probability of the various models (Hosmer and Lemeshow 2000).

We $\log _{10}$ transformed area, species richness, and isolation $+1 \mathrm{~m}$ for each lake before analysis (Lomolino 2001). Regression statistics were conducted in SAS 9.1 (SAS Institute 2003, Cary, NC, USA) and two tailed alpha level was set to 0.05 .

\section{Results}

Totally we recorded 24 summer waterbird species and 1486 individuals in the 38 lakes (Additional file 2: Table S2). The rarefaction curve was an asymptotic line, which indicated that our sample effort was sufficient to count waterbird species in these lakes (Fig. 2).

The most common waterbird species were Little Grebe (Tachybaptus ruficollis, 310 individuals in 37 lakes), Common Moorhen (Gallinula chloropus, 307 individuals in 


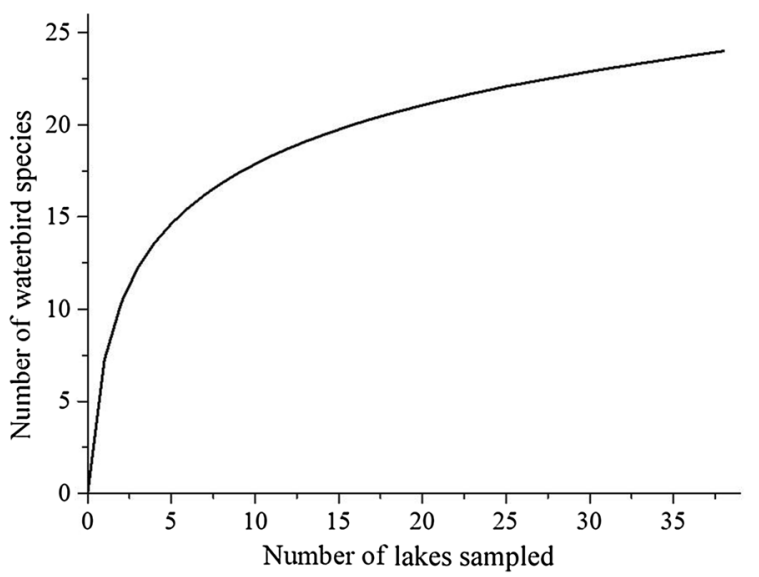

Fig. 2 Summer waterbird species accumulation curve of 38 subsidence lakes in Huainan and Fuyang, Anhui, China, 2016

36 lakes), Black-crowned Night-Heron (Nycticorax nycticorax, 189 individuals in 24 lakes) and Whiskered Tern (Chlidonias hybrid, 175 individuals in 24 lakes). Mean lake area was $129.8 \pm 26.1$ ha (SE, range: 5.6-933.9 ha). Mean lake age was $11.3 \pm 1.3$ years (range: $2-30$ years). Mean distance from subsidence lakes to natural water bodies was $1210.3 \pm 211.5 \mathrm{~m}$ (range: 0-6230 m, Additional file 1: Table S1).

Results from multivariable regression and model selection method were consistent, which showed that area (slope $=0.164 \pm 0.059, F=8.50, p=0.006, R^{2}=0.164$ ) had a positive effect on species richness (Tables 1, 2, Fig. 3a), disturbance (slope $=-0.109 \pm 0.032, F=6.78, p=0.013$, $R^{2}=0.159$ ) and isolation (slope $=-0.042 \pm 0.020$, $\left.F=4.31, \quad p=0.045, \quad R^{2}=0.076\right)$ had negative effects on species richness (Tables 1,2 , Fig. $3 b, c)$. Lake age (slope $=0.003 \pm 0.004, \quad t=0.77, \quad p=0.445, \quad R^{2}=0.016$, Fig. 3d) and lake state (slope $=0.056 \pm 0.064, t=0.88$, $\left.p=0.384, R^{2}=0.021\right)$ did not influence species richness of the lakes.

Further analysis revealed that lakes with intermediate disturbance had higher species richness than lakes under low aquaculture disturbance when area sizes below 100 ha. Lakes under lower aquaculture disturbance had a steeper slope than lakes under intermediate aquaculture disturbance $(0.249$ vs. 0.135$)$, as a result, species richness of lakes under low aquaculture disturbance was higher than lakes under intermediate aquaculture disturbance when lake size exceeded 100 ha. Lakes under high disturbance were always having lower species richness in all circumstances than lakes under low and intermediate disturbances (Fig. 4).

\section{Discussion}

The species-area curve is one of the best documented patterns in community ecology and also central to the theory of island biogeography (MacArthur and Wilson 1963, 1967), which assumes species richness increased with habitat patch area and connectivity. In this study, we confirmed that summer waterbird species richness was positively related with area and negatively related with isolation in 38 post-mining subsidence lakes. Moreover, we also found that human disturbance negatively influenced the existing patterns of species richness, while lake age or lake state (still sinking or not) did not affect species richness.

In consistent with our predictions, species richness increased with lake area and decreased with isolation. The increase in species richness with increasing area had been recurring reported in taxa as diverse as bacteria, plants and animals (Storch et al. 2012; Wagner et al. 2014; Economo et al. 2016). Three explanations had been proposed to account for the behind mechanisms: the sampling hypothesis (Rosenzweig 1995), the habitat heterogeneity hypothesis (Connor and Mccoy 1979) and the equilibrium theory of island biogeography (MacArthur and Wilson 1967). Our results showed that summer bird richness increased with increased lake area and decreased isolation, which supported the area per se theory. Lakes with greater area sizes might provide more niches than smaller lakes. Relatively small variance was explained by isolation in this study $\left(R^{2}=0.076\right)$. This could be attributed to the relatively shorter distances between our study lakes and natural water bodies, or a more complex connectivity (i.e. landscape structure) between lakes from birds' own perspective of view (Tischendorf and Fahrig 2000, 2001). We did not test the habitat heterogeneity and sampling effort hypothesis because of lack of data. We encourage further investigation on the effects

Table 1 Summary of multivariable regression selected by stepwise method and Akaike' Information Criterion adjusted for small sample size on summer waterbird richness of 38 post mining subsidence lakes, Anhui, China, 2016

\begin{tabular}{lccrrr}
\hline Variable & Estimate & SE & Partial $\boldsymbol{R}^{\mathbf{2}}$ & Model $\boldsymbol{R}^{\mathbf{2}}$ & $\boldsymbol{F}$ \\
\hline Area & 0.164 & 0.059 & 0.164 & 0.164 & 0.50 \\
Disturbance & -0.109 & 0.032 & 0.159 & 0.323 & 0.78 \\
Isolation & -0.042 & 0.020 & 0.076 & 0.399 & 0.043 \\
\hline
\end{tabular}



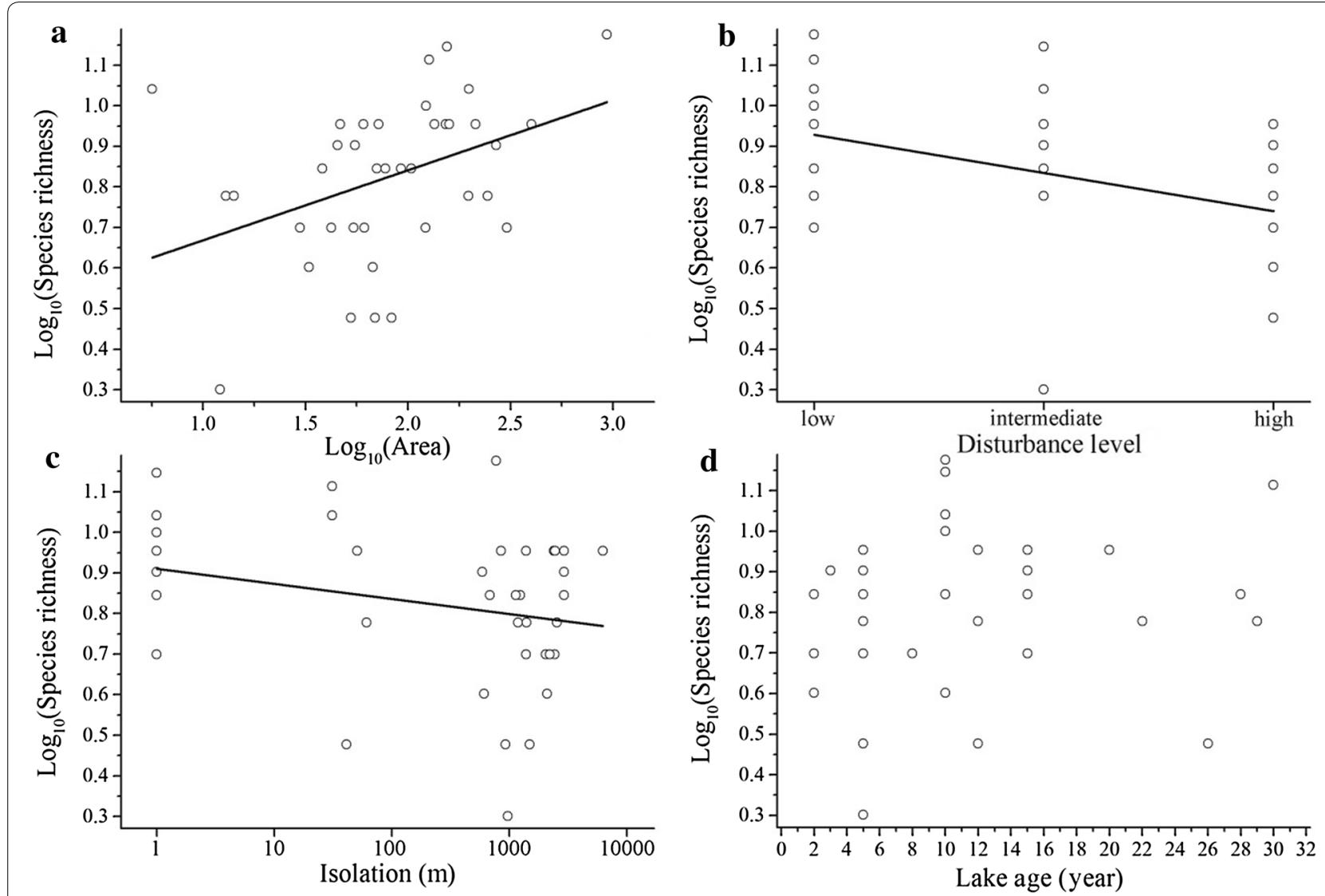

Fig. 3 Linear regression of summer waterbird species richness against 38 post-mining subsidence lakes' area (a), disturbance (b), isolation (c) and lake age (d), Anhui, China, 2016. Figures with black line showed independent variable has a significant effect on species richness $(p<0.05)$

Table 2 Model selection results, ranked by change in Akaike's Information Criterion $\left(\Delta \mathrm{AIC}_{\mathrm{c}}\right)$ adjusted for small sample sizes and Akaike weights $\left(w_{i}\right)$, used to evaluate influences on summer waterbird species richness in 38 subsidence lakes in Huainan and Fuyang, Anhui, China, 2016

\begin{tabular}{lcccc}
\hline Models & AIC & $\mathbf{A I C}_{\mathbf{c}}$ & $\mathbf{\Delta A I C}_{\mathbf{c}}$ & $\boldsymbol{w}_{\boldsymbol{i}}$ \\
\hline Isolation+area + disturbance & -136.0 & -135.29 & 0.00 & 0.79 \\
$\begin{array}{l}\text { Area + isolation+ distur- } \\
\text { bance+ state+ age }\end{array}$ & -134.0 & -132.13 & 3.17 & 0.16 \\
Disturbance & -127.2 & -127.09 & 8.21 & 0.01 \\
Area & -127.0 & -126.89 & 8.41 & 0.01 \\
Area+isolation & -126.9 & -126.56 & 8.74 & 0.01 \\
Age+ state+ disturbance & -125.1 & -124.39 & 10.90 & 0.00 \\
Isolation & -123.2 & -123.09 & 12.21 & 0.00 \\
State & -121.5 & -121.39 & 13.91 & 0.00 \\
Age+ state & -121.7 & -121.36 & 13.94 & 0.00 \\
Age & -121.3 & -121.19 & 14.11 & 0.00 \\
\hline
\end{tabular}

of habitat heterogeneity as this has been found to be an important factor in determining species richness pattern in some other studies (Power 1972; Fox and Fox 2000).

Although the fact that larger areas contain more species than smaller ones is quite obvious, the shape and slope of the species-area relationship have remained largely unexplained (Storch et al. 2003). The slope of species-area relationship found in this study (0.16) was lower compared with results in most of other studies, which was usually between 0.20 and 0.40 (Connor and Mccoy 1979; Economo et al. 2016). This might be because post-mining subsidence lakes in our study area are relatively small. Many studies had concluded that slope of species-area relationship was scale dependent, with a more gentle slope (Palmer and White 1994; Scheiner 2003) and more frequent extinction probabilities in smaller systems (Simberloff 1976). Waterbirds are very mobile animal groups and species found in this study were mostly general species. These might also 


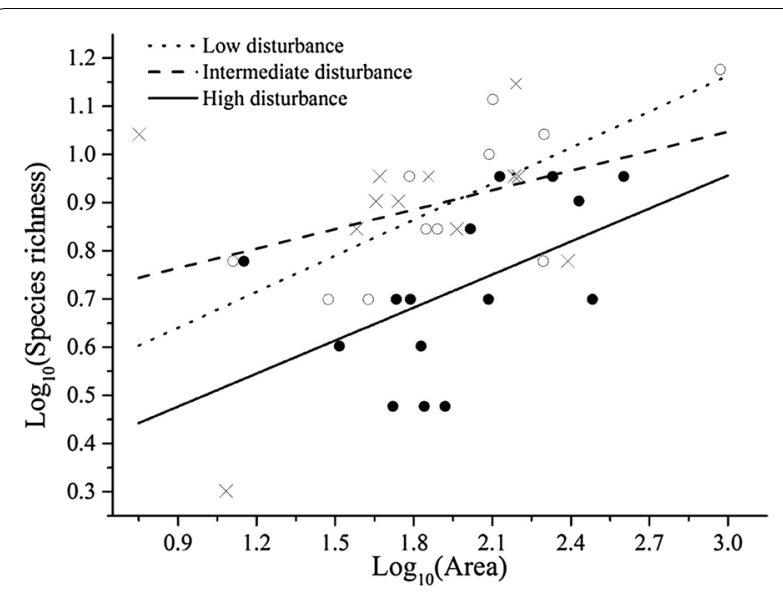

Fig. 4 Effects of aquaculture disturbance on the summer waterbird species-area relationship at 38 post-mining subsidence lakes, Anhui, China, 2016. Cross: low disturbance; open circle: intermediate disturbance; black circle: high disturbance

contribute to similar species composition, lower rates of species turnover among lakes, and thus a gentle slope of species-area relationship.

In accord with our prediction, aquaculture had a significantly negative effect on species richness. Extensive aquaculture in this study might has both direct and indirect effects on species richness. On the one hand, aquaculture activities might directly disturb waterbirds and reduce their resource utilization. On the other hand, aquaculture usually needs to build dike, thus destroy littoral aquatic plants, which indirectly decrease waterbird richness through reducing their resource availability. The effect of aquaculture might not always be detrimental to species richness. For example, Feaga (2014) investigated abundance of wintering waterbirds, seeds, and invertebrates in six production and idled aquaculture facilities and found that aquaculture impoundments produced suitable conditions for waterbirds in terms of food and habitat. In our study system, suitable habitats for most waterbirds (i.e. shallow water) were likely to be destructed as deep waters (usually more than $1 \mathrm{~m}$ ) were preferred for fisheries. Our results also suggested the effect of aquaculture on species richness was scale dependent (Fig. 3). Species richness was always lower under high disturbance level compared with under low and intermediate disturbance levels. However, species richness was higher for lakes under intermediate disturbance than lakes under low disturbance when lake area was smaller than 100 ha. This result was in consistent with the intermediate disturbance hypothesis (Connel 1978), which assumes species number was highest under intermediate disturbance. Species richness in lakes under low disturbance exceeded intermediate disturbed lakes when lake area larger than 100 ha. This might be because that a greater diversity of habitats existed in bigger lakes compared with smaller ones.

Contrary to our prediction, we did not found lake age affect waterbird species richness. This was surprising as our study sites represented an age gradient of 30 years and secondary successional theory predicts an increase in species richness with the succession of systems (Odum 1969; Brown and Southwood 1987). Vegetation composition and structure were found to be important in affecting waterbird habitat selection and utilization (Lantz et al. 2010; Ma et al. 2010). However, aquaculture activities were likely to impede the vegetation growth and spread, and also keep them in an early successional stage, which might impede us finding a relationship between lake age and species richness in our study system. Despite aquaculture could increase resource availability for some fish eating species, such as Little Grebe and Great Crested Grebe (Podiceps cristatus), more profound negative effects might come through both destroying littoral vegetation for dike construction and incurring competition for food resources between waterbirds and fishes (Scheffer et al. 2006).

Despite the significant effects of area, aquaculture disturbance and isolation have been found in our study, relatively low explanation abilities (total $R^{2}=0.399$ ) suggested variables that were not incorporated in our study might also have important influences on species richness. Habitat heterogeneity, both from the lake per se and lake connectivity, could play important roles in shaping summer waterbird communities. And the various human disturbances, such as cultivation category and extensity, traffic flow, and other unpredictable human activities, such as fishing, which frequently occurred around these lakes would also have profound effects on habitat use of summer waterbirds. We encourage a more comprehensive study to incorporate all these factors to understand waterbird species richness of these subsidence lakes in the future.

\section{Conclusions}

Summer waterbird species richness in 38 post-mining subsidence lakes was positively related with lake area and negatively related with isolation. Aquaculture activity had a negative effect on species richness and the effect on species richness was complicated, with the highest species richness found in intermediate disturbed lakes less than 100 ha, and low disturbed lakes above 100 ha. Lakes under high disturbance always had lowest species richness. Lake age since formation has no significant effect on species richness, which might attribute to that aquaculture activities impede lake vegetation growth and spread, and thus keep these lakes in an early successional stage. 


\section{Additional files}

Additional file 1: Table S1.Species richness, area size, disturbance, isolation, age, and state of the 38 subsidence lakes used in linear regressions in this manuscript

Additional file 2: Table S2. Waterbird species and numbers found at the 38 investigated post-mining subsidence lakes in Huainan and Fuyang, Anhui, China, 2016

\section{Authors' contributions}

$J Z$ and LZ conceived the research project. JZ collected and analyzed the data. JZ and LZ wrote and approved the manuscript. Both authors read and approved the final manuscript.

\section{Acknowledgements}

We thank the anonymous local villagers who gave us a ride during our investigations.

\section{Competing interests}

The authors declare that they have no competing interests.

\section{Availability of data and materials}

The datasets used and/or analyzed during the current study are included in the paper.

\section{Consent for publication \\ Not applicable.}

\section{Ethics approval and consent to participate}

The waterbird investigations comply with the current laws of China in which they were performed.

\section{Funding}

This work was supported by the National Natural Science Foundation of China (Grant No. 31472020).

Received: 29 September 2017 Accepted: 7 March 2018 Published online: 09 March 2018

\section{References}

Amato KR, Yeoman CJ, Kent A, Righini N, Carbonero F, Estrada A, Gaskins HR, Stumpf RM, Yildirim S, Torralba M. Habitat degradation impacts black howler monkey (Alouatta pigra) gastrointestinal microbiomes. ISME J. 2013;7:1344-53

Akaike $\mathrm{H}$. Information theory and an extension of the maximum likelihood principle. In: Petrov BN, Csaki F, editors. Proceeding of the 2nd international symposium on information theory. Budapest: Akademiai Kiado; 1973. p. 267-81.

Badano El, Regidor HA, Núñez HA, Acosta R, Gianoli E. Species richness and structure of ant communities in a dynamic archipelago: effects of island area and age. J Biogeogr. 2005;32:221-7.

Brown VK, Southwood TRE. Trophic diversity, niche breadth and generation times of exopterygote insects in a secondary succession. Oecologia. 1987;56:220-5.

Burnham KP, Anderson DR. Model selection and multimodel inference: a practical information-theoretic approach. Berlin: Springer; 2002.

Bush MB, Whittaker RJ. Krakatau: colonization patterns and hierarchies. J Biogeogr. 1991;18:341-56

Connel JH. Diversity in tropical rain forests and coral reefs-high diversity of trees and corals is maintained only in a non-equilibrium state. Science. 1978;199:1302-10.

Connor EF, McCoy ED. The statistics and biology of the species-area relationship. Am Nat. 1979;113:791-833.
Crowe TM. Lots of weeds: insular phytogeography of vacant urban lots. J Biogeogr. 1979;6:169-81.

Durrett R, Levin S. Spatial models for species-area curves. J Theor Biol. 1996;179:119-27.

Economo EP, Janda M, Guénard B, Sarnat E. Assembling a species-area curve through colonization, speciation and human-mediated introduction. J Biogeogr. 2016;44:1088-97.

Feaga JS. Winter waterbird use and food resources of aquaculture lands in Mississippi. Mississippi State: Master of Science, Mississippi State University; 2014.

Fox BJ, Fox MD. Factors determining mammal species richness on habitat islands and isolates: habitat diversity, disturbance, species interactions and guild assembly rules. Glob Ecol Biogeogr. 2000;9:19-37.

Frey J, Bogan M, Yates T. Mountaintop island age determines species richness of boreal mammals in the American Southwest. Ecography. 2007:30:231-40.

Graham MH. Confronting multicollinearity in ecological multiple regression. Ecology. 2003;84:2809-15.

Hiddink JG, Jennings S, Kaiser MJ, Queirós AM, Duplisea DE, Piet GJ. Cumulative impacts of seabed trawl disturbance on benthic biomass, production, and species richness in different habitats. Can J Fish Aquat Sci. 2006;63:721-36.

Horsák M, Hájek M, Spitale D, Hájková P, Dítě D, Nekola JC. The age of island-like habitats impacts habitat specialist species richness. Ecology. 2012;93:1106-14

Hosmer D, Lemeshow S. Applied logistic regression. 2nd ed. New York: Wiley; 2000.

Hubbell SP. A unified theory of biogeography and relative species abundance and its application to tropical rain forests and coral reefs. Coral Reefs. 1997;16:S9-21

Krauss J, Alfert T, Steffan-Dewenter I. Habitat area but not habitat age determines wild bee richness in limestone quarries. J Appl Ecol. 2009:46:194-202.

Kreft H, Jetz W, Mutke J, Kier G, Barthlott W. Global diversity of island floras from a macroecological perspective. Ecol Lett. 2008;11:116-27.

Lantz SM, Gawlik DE, Cook MI. The effects of water depth and submerged aquatic vegetation on the selection of foraging habitat and foraging success of wading birds. Condor. 2010;112:460-9.

Lomolino MV. The species-area relationship: new challenges for an old pattern. Prog Phys Geogr. 2001;25:1-21.

Ma Z, Cai Y, Li B, Chen J. Managing wetland habitats for waterbirds: an international perspective. Wetlands. 2010;30:15-27.

MacArthur RH, Wilson EO. An equilibrium theory of insular zoogeography. Evolution. 1963:17:373-87.

MacArthur RH, Wilson EO. The theory of island biogeography. Princeton: Princeton University Press; 1967

Odum EP. The strategy of ecosystem development. Science. 1969;164:262.

Palmer MW, White PS. Scale dependence and the species-area relationship. Am Nat. 1994;144:717-40.

Power DM. Numbers of bird species on the California islands. Evolution. 1972:26:451-63.

Rejmánek M, Rejmánková E. Biogeography of artificial islands: effects of age, area, elevation, and isolation on plant species richness. Preslia. 2002;74:307-14.

Rosenzweig ML. Species diversity in space and time. Cambridge: Cambridge University Press; 1995

Ross KA, Fox BJ, Fox MD. Changes to plant species richness in forest fragments: fragment age, disturbance and fire history may be as important as area. J Biogeogr. 2002;29:749-65.

Rybicki J, Hanski I. Species-area relationships and extinctions caused by habitat loss and fragmentation. Ecol Lett. 2013;16:27-38.

Scheffer M, Van Geest G, Zimmer K, Jeppesen E, Søndergaard M, Butler M, Hanson M, Declerck S, De Meester L. Small habitat size and isolation can promote species richness: second-order effects on biodiversity in shallow lakes and ponds. Oikos. 2006;112:227-31.

Scheiner SM. Six types of species-area curves. Glob Ecol Biogeogr. 2003;12:441-7.

Simberloff D. Species turnover and equilibrium island biogeography. Science. 1976;194:572

Sousa WP. The role of disturbance in natural communities. Annu Rev Ecol Syst. 1984;15:353-91. 
Storch D, Izling AL, Gaston KJ. Geometry of the species-area relationship in central European birds: testing the mechanism. J Anim Ecol. 2003;72:509-19.

Storch D, Keil P, Jetz W. Universal species-area and endemics-area relationships at continental scales. Nature. 2012;488:78-81.

Tittensor DP, Micheli F, Nyström M, Worm B. Human impacts on the speciearea relationship in reef fish assemblages. Ecol Lett. 2007:10:760-72.

Tischendorf L, Fahrig L. On the usage and measurement of landscape connectivity. Oikos. 2000;90:7-19.

Tischendorf L, Fahrig L. On the use of connectivity measures in spatial ecology. A reply. Oikos. 2001;95:152-5.

Valente LM, Etienne RS, Phillimore AB. The effects of island ontogeny on species diversity and phylogeny. Proc Biol Sci. 2014;281:20133227.
Vera CF, Rocha CF. Habitat disturbance and small mammal richness and diversity in an Atlantic rainforest area in southeastern Brazil. Brazil J Biol. 2006;66:983-90.

Wagner CE, Harmon L, Seehausen O. Cichlid species-area relationships are shaped by adaptive radiations that scale with area. Ecol Lett. 2014;17:583-92. Wan WJ, Zhou LZ, Ping L. Impact of coal mining subsidence on species composition and diversity of avian community. Sichuan J Zool. 2015;34:773-9 (in Chinese)

Williamson M. Relationship of species number to area, distance and other variables. Dordrecht: Springer; 1988.

Yuan Y, Zeng G, Liang J, Li X, Li Z, Zhang C, Huang L, Lai X, Lu L, Wu H. Effects of landscape structure, habitat and human disturbance on birds: a case study in East Dongting Lake wetland. Ecol Eng. 2014;67:67-75.

\section{Submit your next manuscript to BioMed Central and we will help you at every step:}

- We accept pre-submission inquiries

- Our selector tool helps you to find the most relevant journal

- We provide round the clock customer support

- Convenient online submission

- Thorough peer review

- Inclusion in PubMed and all major indexing services

- Maximum visibility for your research

Submit your manuscript at www.biomedcentral com/submit 